\title{
Analysis and design improvement of high class roads' arched sections in Poland
}

\author{
Joanna Żukowska ${ }^{1, *}$, Paweł Słomiński ${ }^{1}$ \\ ${ }^{1}$ Gdańsk University of Technology, Faculty of Civil and Environmental Engineering, 11 Narutowicza Street, 80-213 Gdańsk, Poland
}

\begin{abstract}
Although Polish road network standards, in particular higher classes of roads are improving dynamically the number of fatalities on the network is still higher that EU's average. Ensuring road safety and high maintaining standards is a complex issue and one that poses a major challenge for all road authorities. Road accidents at high speed roads characterize specially serious material and social consequences, thus research into road safety is of a special interest and numerous analyses and debates are being conducted worldwide as well as in Poland. In this paper the authors provide the results and recommendations coming from the analysis of accidents which happened on high speed roads during the heavy rainfall. The analysis of incidents which happened on sections with changing vertical alignment shows that a properly designed road geometry does not eliminate road accidents or conflicts.
\end{abstract}

\section{Introduction}

Ensuring road safety and high maintaining standards is a complex issue and one that poses a major challenge for all road authorities [1]. Road accidents at high speed roads characterise specially serious material and social consequences, thus research into road safety is of a special interest and numerous analyses and debates are being conducted worldwide as well as in Poland. Globally motorway systems generate nearly 50 million persons injured in traffic accidents every year, not including the 1.2 million deaths [2]. According to Police statistics traffic injury is the single leading cause of unintentional death in the first 5 decades of human life.

Traffic safety management is a systematic process that aims to reduce the occurrence and severity of traffic accidents. The interaction between a man and a car within road traffic systems is unstable and poses a great challenge to highway safety management. The key for increasing the safety of highway systems is to design, build, and maintain them to be far more tolerant of the average range of this man/car interaction with motorways. Technological advancements in highway engineering have improved the design, construction, and maintenance methods used over the years. These advancements have allowed for newer highway safety innovations. One of them is being considered within this paper. The design stage is crucial for achieving the most appropriate location, alignment, and shape of a motorway. The design process involves the consideration of three major factors: human, vehicular, and roadway- and how these factors interact to provide a safe road [3]. Human factors include e.g. reaction time for braking and steering, visual acuity for traffic signs and signals, and car-following behaviour. Vehicle considerations include vehicle shape and dynamics that are essential for determining lane width and maximum slopes, and for the selection of design vehicles.

\section{Road geometry and safety}

Geometric design aims at optimizing the efficiency and safety while minimizing cost and environmental impacts. The process of geometric motorway design can be broken into three main parts: design of the alignment, profile, and cross-section of the road. Combined, the three elements provide a three-dimensional layout for a roadway. The alignment is the track of the road, defined as a series of horizontal tangents and curves. The profile is the vertical aspect of the roadway, including crest and sag curves, and the straight grade lines connecting them. Last bit now least the crosssection shows the position and number of vehicle and bicycle lanes and well as sidewalks, along with their cross slope or banking. Cross sections also show drainage features which are of the special interest of this paper as the element of design which, especially on a high speed roads, may strongly influence safety level [4].

The problem of water on the road surface is as follow: after falling onto road surfaces, rainfall runoff drains to the lowest point and in moving across the road surface forms a layer of water of varying thickness. This water can generate special problems to the road users. Splash and heavy spray are thrown up by moving cars, reducing visibility, while the water on the pavement reduces friction between the tires of the vehicles and road surface. Excessive water on the pavement, whether ponded or flowing, can represent a real risk of aquaplaning or the build-up of a layer of water between the vehicle tire and the road surface, which may lead to a

\footnotetext{
* Corresponding author: joanna.zukowska $@$ pg.edu.pl
} 
total loss of grip. While part of road surface drainage, aquaplaning is a critically important aspect of road surface drainage.

Accidents tend to be more frequent on road sections where a sudden change in road character, maintenance standards or surrounding conditions violates the driver's expectations. Aquaplaning may be one of these circumstances. A thin layer of water between the wheels of the car and the road surface may lead to a loss of traction that prevents the car from responding to control inputs. If it occurs to all wheels simultaneously, the car becomes an uncontrolled sled.

In Polish road design guidelines water on the roadway and how it is drained off is addressed in particular in relation to vehicles, traffic and tire grip under special conditions, while in other countries also the official instructions show the need to consider of changing vertical alignments of the road. Some analysis were conducted worldwide and the synthesis of their results is provided in the article. In this paper the authors present some construction methods to improve those road sections which were designed properly but still during the rainfall the accidents appear on them. In fact only two countries introduced guidelines on how to design the construction. These are Germany and Sweden. The guidelines of the Supreme Building Office of Bavaria's Ministry of the Interior, "Safe street design" describe how rainfall and driver behavior contribute to road accidents and what are the ways to design and redesign roads to increase safety [5]. Sweden's Road and Street Design Guidelines "Råd för Vägars och gators utformning" offer the so called "airscrew" solution where there is a gradient to be adjusted [6]. This may be applied on roads with one or more lanes. On November $19^{\text {th }} 2008$ the EU Parliament announced Directive 2008/96 / EC on road infrastructure safety, which obligate the Member States to introduce safety management rules on European transport network. Unfortunately, in Poland the legislative changes to the present are not in force on the whole road network. Thus, at least within the proper design and maintenance of sections with changing vertical alignment it is still a good moment to gain experiences and recommend best practices [7], [8].

\section{Review of best practices}

Tackling with the problem of water on the roadway several practices has been introduced in Poland and abroad. There are some of them introduced in this section.

\subsection{Use of dedicated vertical signs}

Special caution is advised when using sites with poor drainage during rainfall. This is due to poor workmanship, wrong interpretation of technical conditions for toll motorways and changing cross slopes. An experimental warning sign is proposed (Fig. 1).

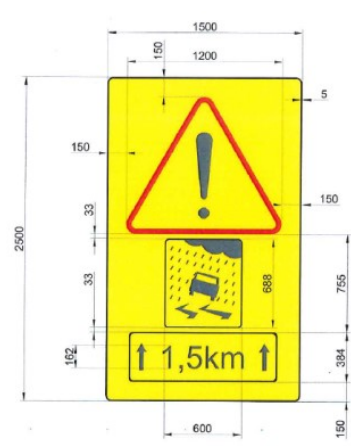

Fig. 1. Experimental signage to "inform about deteriorated conditions during rainfall"

\subsection{Milling}

Surface milling machines can be used to scarify the wearing course in order to correct water drainage. This is done by cutting off the near surface of the wearing course at several or about a dozen millimeters deep. Surface milling is an invasive method which cuts into the wearing course, opens up the pores between the aggregate's grains and polishes them. Milling can also make riding uncomfortable for two wheelers or even cause vehicles to lose steerability which in turn deteriorates road safety. Once uncovered, the aggregate is subjected to penetration of water, traffic and variable air temperature. As a consequence, the loss of binder may cause the grains to detach affecting the mineral and asphalt mix.

The work can be done using a Chinese milling machine Masalta model MC8-4, with a $5.5 \mathrm{KM}$ Honda engine, working width of $200 \mathrm{~mm}$ and $20 \mathrm{~mm}$ milling depth. The machine is mainly used for scarifying horizontal road markings and treating the road surface. The next product which is available in Poland is the FA300 milling machine manufactured by HYDROG Zaktad Budowy Maszyn from Łódź. When the milling is only a few millimeters deep, the results during heavy rainfall have hardly any effect at all. The cost of the work including provisions to protect the site, restricted access to the road and mediocre drainage performance make it a short-term solution and a fairly costly one as well.

\subsection{Proper vertical alignment}

An analysis of incidents which happened during rainfall on sites with changing vertical alignment shows that a properly designed road geometry does not eliminate road incidents or conflicts. This problem is also covered in an analysis conducted by road safety experts. In addition, a road profile which meets the regulations will cost nearly just as much in road works costs as the "envelope" solution, but the impact on road safety is fairly good. The total cost is app. PLN 750,000. 


\subsection{Airscrew and envelope solution}

By analyzing worldwide drainage solutions in places of a changing vertical alignment the authors has reached for technical regulations that are being used in the majority of European countries, Russia, the United States and Canada. From the analyzed eleven countries only two have guidelines for the "envelope" or "airscrew" solution. They were Swedish and German guidelines. It is not just coincidence that these countries are the most advanced in road safety.

\section{Swedish guidelines}

Swedish road and street design guidelines "Råd för Vägars och gators utformning" include a so called "airscrew" solution (Fig. 2) where there is a gradient to be adjusted. This is applied on one way roads with one or more lanes. In other cases the airscrew solution should be applied on an existing drainage for more comfortable driving. For any road width, the axis of "airscrew" rotation depends on the minimal length as illustrated in the formula below:

$$
U=\Delta \mathrm{E} / \omega *(\mathrm{VR}+10) / 360
$$

where: $\mathrm{U}$ - length of inclination $(\mathrm{m}), \Delta \mathrm{E} \%$ - difference in gradient $(\%), \omega-$ change of angle of rotation per unit of time, $\leq 0.038, \mathrm{VR}$ - reference speed $(\mathrm{km} / \mathrm{h})$.

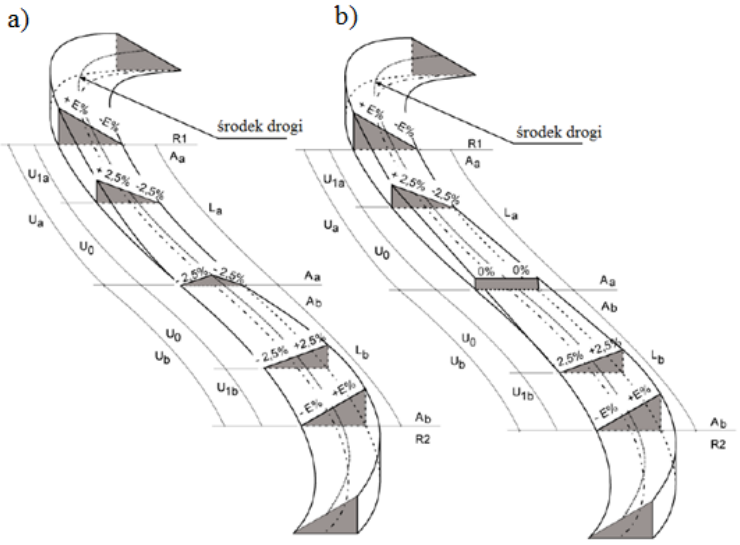

Fig. 2. "Airscrew" design: a) classic airscrew, b) airscrew with shifted zero points [6] ("srodek drogi" (pol.) = axe of the road).

\section{German guidelines}

The guidelines of the Supreme Building Office of Bavaria's Ministry of the Interior, "Safe street design" (Oberste Baubehoerde im Bayerischen Staatsministerium des Innern, Verkehrssichere strassengestaltung) describe how rainfall and driver behavior contribute to road accidents. Water determines grip between the tire and road surface. When turning the wheel or braking, the risk of skidding increases. The document also includes recommendations presented as a set of rules [5]. Where slopes are oppositely directed on roads, the minimum gradient along the road should be $\mathrm{s} \geq 0.7 \%$ or even $\mathrm{s} \geq$
$1.0 \%$. This solution is designed to prevent water being drained from lower zones. To ensure sufficient road drainage, the guidelines suggest a minimal gradient of $0.2 \%(0.5 \%$ is better $)$ which is good enough to prevent aquaplaning. Another solution is to use vertical alignment deviation tolerance - q to $+\mathrm{q}$. It is, however, very complicated to design and build and mistakes are more likely to be made (Fig. 3).

During rainfall the water flows across the entire road width in micro wheel tracks following the downward gradient of the vertical alignment. " 0 " gradients in ramp area cause water to pond momentarily. To improve drainage, the width of the road should be divided into working sections.

The German guidelines describe how repairs should be made to eliminate the ponding of water. The solution was applied on the A8 motorway in 2003. diagram of the solution on the A8.

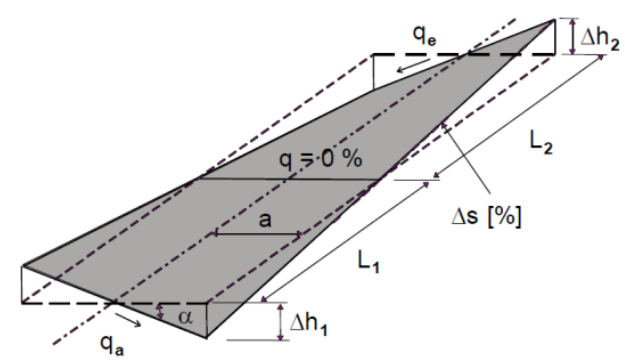

Fig. 3. Diagram of an envelope change of vertical alignment [5].

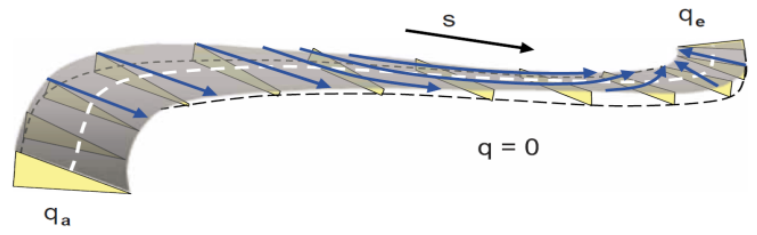

Fig. 4. Diagram of water concentration next to the ramp for " 0 " change of the vertical alignment, as required in the German guidelines of Bavaria's Ministry [5].
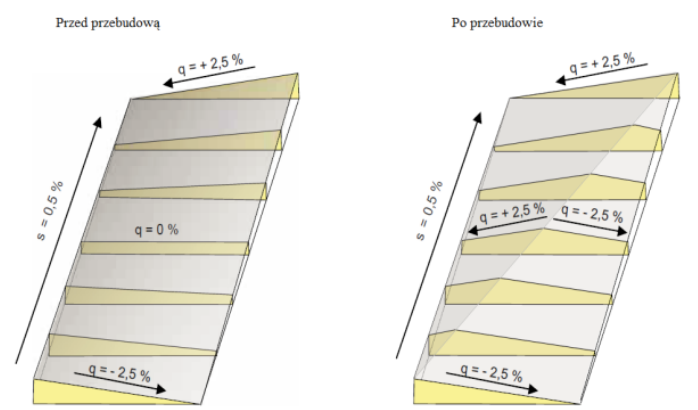

Fig. 5. Example of an envelope applied in 2003 on the A8 motorway. 
According to the data of Bavaria's Ministry before the improvement, i.e. between 2000-2002, there were app. 42 accidents recorded in the analyzed area and after the improvement between 2004-2006 there were only 5 accidents related to the problem of water drainage. Figure 5 shows a To ensure good results, the improvement should be designed as follow: move the low gradient vertical alignment to where water can be drained off more easily and increase the approach by increasing the gradient from 0 to $2.5 \%$ which will also help to avoid aquaplaning or design an "envelope" relative to height "q".

\section{Solution for Poland}

In Poland considering the costs of the work, maintenance and additional charges such as road access and use of road charge, the German solution should be modified with the envelope shifted from $1.5 \%$ as opposed to Germany's $2.5 \%$. If treated like this, the costs to disassembly the existing road infrastructure can be reduced. This is because of the technical working width of the asphalt spreader (Fig.6) which meant that the existing road infrastructure had to be removed which also included the removal of central reservation or roadside safety barriers near the peak of the envelope.

This solution will partly eliminate aquaplaning and the water level on the road which may cause this phenomenon can be reduced by applying cross slope [9], [10]. For a gradient of $2 \%$ the resulting layer will be fairly safe and less than $2 \mathrm{~mm}$. Fig. 7 shows the road geometry before the improvement with blue illustrating the zone of water ponding. The zone is app. 30 running meters which causes aquaplaning for high speeds and heavy rainfall on a long section before the curve.

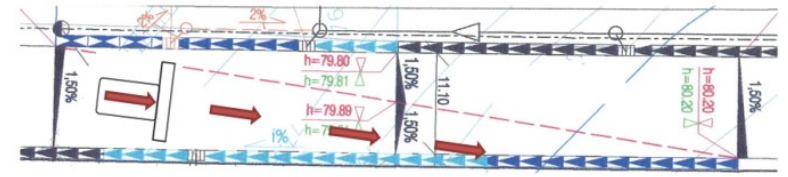

Fig. 6. A section of the design to show the route of the asphalt spreader.

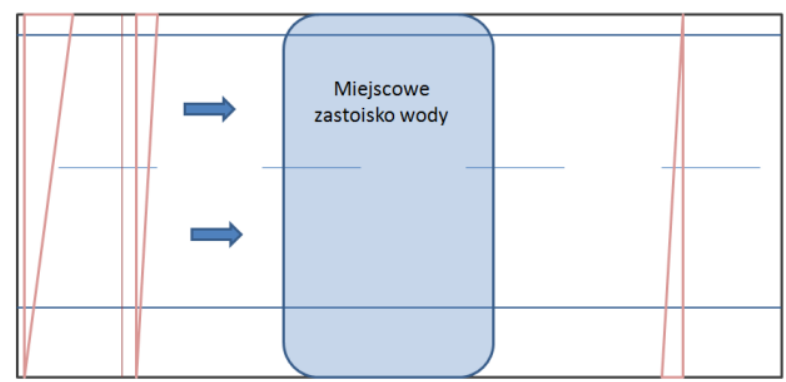

Fig. 7. Condition of the roadway before the repairs with a significant area affected by the ponding of water ("Miejscowe zastoisko wody" (pol.) = the ponding of water).

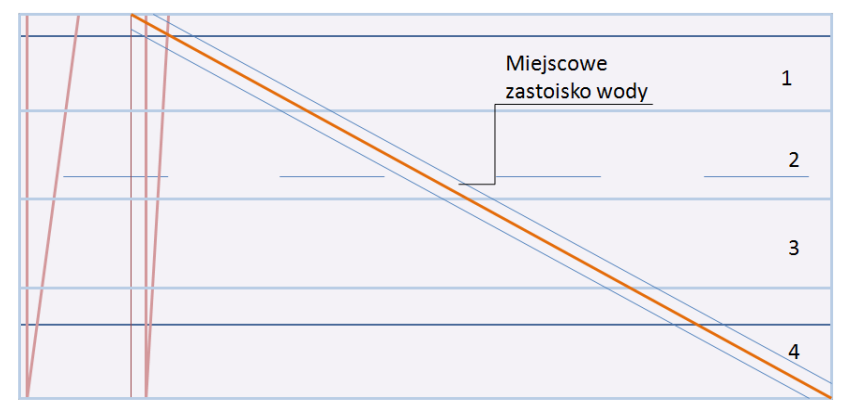

Fig. 8. The approved method for dividing the road works zone into 4 working plots ("Miejscowe zastoisko wody" (pol.) = the ponding of water).

Fig. 8 shows the solution adjusted to the needs of the actual work on the road. The road is divided into 4 working sections to match the technical working width of the asphalt spreader. The resulting ponding of water is now app. $30 \mathrm{~cm}$ long as opposed to 30 running meters before the treatment.

The road works were conducted during traffic and the road was closed twice app. 6 days each time. First the emergency lane and $1.5 \mathrm{~m}$ of the slow lane were closed. After the work was completed the work was moved to the fast lane and the remaining $2.0 \mathrm{~m}$ of the slow lane. Spreading, moving and change of traffic went on for app. 26 hours per each cycle.

\section{Conclusion and recommendations}

Road accidents at high speed roads characterize specially serious consequences, thus research into road safety is of a special interest [11]. Even if we design and introduce changes to the road gradients correctly, it is uncertain whether unfavorable conditions such as heavy rainfall and excessive speed will not lead to a road accident. Such situations are not uncommon in Poland, and the proof is that road administration of motorways A1 and A4 and regional road 216 has noticed the increased risks within this issue. Thus specially dedicated vertical signs has been introduced in a number of road sections on these roads.

After introducing several years ago the envelope or propeller solutions at some of Polish highway sections, we are sure, supported by German or Swedish experience, that the solution is effective and improves safety. Monitoring of the A1 motorway sections, on which the envelope solution was applied, largely showed total elimination of road accidents during rainfall or immediately after the fall of precipitation. It was also found that the solution is effective only for two lanes roads. In one of the observed places, where there is additionally an ILO inclusion belt, the introduced solution reduced the number of incidents by $62 \%$. At the moment, only vehicles driving at excessively high speed, much higher than allowed, are taking part in this kind of events.

Having this positive experience the next step should be the introduction of regulations. It should go hand in hand with road development and speed increase 
since thanks to this law any shortcomings in the design and implementation of infrastructure in these critical locations would be avoided. The main challenges related to implementation of these solutions include significant financial expenditures (execution, security of works) and finding a contractor who could undertake the professional implementation of road grades.

\section{References}

1. L. Wachnicka, W. Kustra, K. Jamroz, Development of tools for road infrastructure safety management for the provinces (voivodeships) in Poland, 26th Conference on European Safety and Reliability (ESREL) (2016)

2. K. Jamroz, L. Michalski, J. Żukowska, Polish Experience of Implementing Vision Zero, Current Trauma Reports (2017)

3. Consistency Module Engineers Manual. Interactive Highway Design Model Engineer's Manual. Federal Highways Administration (2012)

4. M. Gaudry, S. Himouri, DRAG-ALZ-1, a first model on monthly total road demand, accident frequency, severity and victims by category, and of mean speed on highways, Algeria 1970-2007, Research in Transportation Economics 37, 1 (2013)

5. K. Jamroz, W. Kustra, M. Budzyński, J. Żukowska, Pedestrian Protection, Speed Enforcement and Road Network Structure the key Action for Implementing Poland's Vision Zero, Transportation Research Procedia 14, pp. 3905-3914 (2016)

6. Råd För Vägars och gators utformning, Trafikverkets Publikation 2012 - Road and street design advice (2012)

7. Oberste Baubehoerde im Bayerischen Staatsministerium des Innern, Verkehrssichere strassengestaltung (2008)

8. M.P. Martinez, A. Garcia, A. T. Moreno, Traffic Microsimulation Study to Evaluate Freeway Exit Ramps Capacity, Procedia - Social and Behavioral Sciences 16 (2011)

9. R. Ossowski, K. Gwizdała, Mechanical Properties of a Dike Formed from a Soil-ash Composite, Procedia Engineering, 172 (2017)

10. J. Szulwic, P. Tysiąc, Searching for road deformations using mobile laser scanning, MATEC Web of Conferences, 122 (2017)

11. J. Szulwic, P. Ziółkowski, A. Janowski, Combined Method of Surface Flow Measurement Using Terrestrial Laser Scanning and Synchronous Photogrammetry, Proceedings - 2017 Baltic Geodetic Congress (Geomatics), BGC Geomatics (2017)

12. R. Bergel-Hayat, J. Żukowska J, Road Safety Trends at National Level in Europe: A Review of Timeseries Analysis Performed during the Period 200012, Transport Reviews 35, 5 (2015) 